\title{
In Vitro Self-incompatible-like Response Applied for Protein Identification and Gene Expression Analysis in Citrus Cultivars, Banpeiyu and Hyuganatsu
}

\author{
Yiran Li \\ Interdisciplinary Graduate School of Agriculture and Engineering, University of Miyazaki, 1-1, \\ Gakuenkibanadai-Nishi, Miyazaki 889-2192, Japan \\ Akiha Abe, Takuichi Fuse, and Tomonari Hirano \\ Faculty of Agriculture, University of Miyazaki, 1-1, Gakuenkibanadai-Nishi, Miyazaki 889-2192, \\ Japan \\ Yoichiro Hoshino \\ Field Science Center for Northern Biosphere, Hokkaido University, Kita 11 Nishi 10, Kita-ku, \\ Sapporo, Hokkaido 060-0811, Japan \\ Hisato Kunitake ${ }^{1}$
Faculty of Agriculture, University of Miyazaki, 1-1, Gakuenkibanadai-Nishi, Miyazaki 889-2192,
Japan
}

AdDitional INDEX words. catalase, nano-LC-MS, pollen culture, programmed cell death, reactive oxygen species, stylar crude protein, superoxide dismutase

\begin{abstract}
Self-incompatibility (SI) is an important mechanism in higher plants that promotes outcrossing and prevents self-fertilization. 'Banpeiyu' (Citrus maxima) and 'Hyuganatsu' (Citrus tamurana), two of the Citrus cultivars distributed in Kyusyu, Japan, show gametophytic SI. In this study, we used the Citrus mature pollen culture system and stylar crude protein extracts to simulate compatible (C) and SI responses in 'Banpeiyu' pollen tubes. We analyzed the protein changes in pollen tubes with the $\mathrm{C}$ - and SI-like treatments by nano-liquid chromatography-mass spectrometry (nano-LC-MS); 14 and 27 proteins were identified in C-and SI-like treatments, respectively. We picked up some candidate genes that were particularly prevalent in SI-like treatment and analyzed their expression level changes during C- and SI-like treatments in 'Banpeiyu' and 'Hyuganatsu' pollen tubes. The expression levels of copper/zinc superoxide dismutase (Cu/Zn SOD), manganese SOD (Mn SOD), catalase (CAT), and cysteine protease $(C Y P)$ increased after SI-like treatment. We used a fluorescent probe to visualize reactive oxygen species (ROS) level changes in 'Banpeiyu' and 'Hyuganatsu' pollen tubes after $\mathrm{C}$ - and SI-like treatments and found that 2-hour SI-like treatment induced ROS levels to increase in the pollen tubes of both cultivars. These results suggest that an ROS increase could be one of the key phenomena in the SI response of Citrus and that gene expression changes were responses to ROS generation.
\end{abstract}

Self-incompatibility in angiosperms is known as a mechanism for preventing self-fertilization and promoting outcross pollination by arresting pollen tube growth. One of the SI systems, RNase-mediated gametophytic SI (GSI), is based on the recognition and degradation of self-pollination by interaction between S-locus-encoded proteins from pistil and pollen (Foote et al., 1994; Hiratsuka et al., 2012; Lai et al., 2002; Lee et al., 1994; Murfett et al., 1994; Wheeler et al., 2009).

In recent years, several studies have investigated the cytosolic alterations in pollen tubes exposed to SI response. Reactive oxygen species, a potent signaling molecule, was easily affected by SI response in pollen tubes of Papaver rhoeas (Wilkins et al., 2011) and Pyrus pyrifolia (Wang et al., 2010). The increase of ROS was thought to be a stress response, and a following influx of $\mathrm{Ca}^{2+}$ was detected (Rentel and Knight, 2004). Peroxynitrite, a powerful oxidizing and nitrating agent,

Received for publication 22 Apr. 2015. Accepted for publication 21 May 2015. This study was supported by a Grant-in-Aid for Scientific Research (KAKENHI no. 25660029) from the Japan Society for the Promotion of Science (JSPS).

${ }^{1}$ Corresponding author. E-mail: hkuni@cc.miyazaki-u.ac.jp. was generated in the pollination of Olea europaea, increasing the protein nitration in SI pollen tubes (Serrano et al., 2011). It has been proved that the toxicity of excessive ROS induced by SI response triggers a cascade reaction and finally results in programmed cell death (PCD) in incompatible pollen tubes. PCD is a crucial process to selectively eliminate unneeded or damaged cells for development and tissue homeostasis (Fuchs and Steller, 2011). In apoptosis, one form of PCD, relocalization of cytochrome $\mathrm{c}$ is considered the beginning of the PCD process in mammals; cytochrome $\mathrm{c}$ functions as an activator of procaspase in the apoptosome (Gray, 2004). Although caspase3 is only present in animal PCD, the caspase-3-like/DEVDase displays DEVD (Asp-Glu-Val-Asp) specificity in the SI response of $P$. rhoeas pollen tubes (Thomas and FranklinTong, 2004). Mitochondria collapse, degradation of DNA, ROS burst, and cytoskeleton depolymerization have been observed as SI responses in pollen tubes, and these phenomenas are common characteristics of PCD (Geitmann et al., 2000; Roldán et al., 2012; Wang et al., 2009a; Wilkins et al., 2011).

The Citrus is one of the typical GSI plants, and S-RNase homologues have been cloned from mandarin cultivars, which 
kept the same conserved regions with S-RNase as Solanaceae (Miao et al., 2011). However, it has not been confirmed whether these homologues have functions for GSI. Proteomics and genomics analyses have been widely applied to identify the SI mechanism of Citrus. Distefano et al. (2009) has compared the transcript profiles of style and stigma with/without selfpollination in the Clementine mandarin (Citrus clementina). Although 96 unigenes were identified between the SI 'Comune' and mutated self-compatible 'Monreal', the $S$ gene was not detected. In 'Hyuganatsu', protein expression in the pistils has been identified by matrix-assisted laser desorption/ionization time-of-flight mass spectrometry, and has indicated that the pistils are converted from self-compatible to SI 3 to $5 \mathrm{~d}$ before anthesis (Uchida et al., 2012b). Moreover, for investigation of Citrus pollen tubes, we have established an in vitro pollen culture system (Uchida et al., 2012a) and an in vitro SI-like reaction system using the stylar crude protein extract treatment (Li et al., 2015). It has also been demonstrated that stylar crude protein extracts induced SI response in apple pollen tubes, as well as purified S-RNase protein in vitro (Meng et al., 2014).

In this study, we used strong GSI Citrus cultivars Banpeiyu pummelo and Hyuganatsu, a chance seeding cultivar that may relate to Citrus yuzu, for investigation of the SI response in the pollen tubes. These are economically important fruit cultivars in Kyusyu, Japan, and produce few seeds with self-pollination (Wakana et al., 2004; Yamamoto et al., 2006). To detect the SI-related proteins in the pollen tubes, we obtained the protein expression profiles in 'Banpeiyu' pollen tubes by nano-LC-MS, and identified the proteins between the $\mathrm{C}$ and SI treatments. Transcriptional changes were also analyzed in the genes predicted to participate in the SI responses.

\section{Materials and Methods}

Plant materials. One day before anthesis, buds of 'Banpeiyu' (collected in Spring 2013 and 2014), 'Hyuganatsu' (collected in Spring 2014), and 'Hassaku' (Citrus hassaku) (collected in Spring 2013) were collected from mature trees growing in the experimental field of the University of Miyazaki, Miyazaki, Japan. Anthers of 'Banpeiyu' and 'Hyuganatsu' were separated with tweezers and dried with silica gel overnight in an incubator at $25{ }^{\circ} \mathrm{C}$ until anther dehiscence. Mature pollen grains were stored at $-40{ }^{\circ} \mathrm{C}$ until use. The styles were separated from fresh pistils and prepared for protein extraction as soon as possible.

StYlar CRUde Protein extract preparation. The styles from 'Banpeiyu', 'Hassaku', and 'Hyuganatsu' were prepared for the isolation of crude protein extracts using extraction buffer as described by Li et al. (2015). All extraction operations were done on ice, and isolated protein solution was divided into $100-\mu \mathrm{L}$ portions and stored at $-80^{\circ} \mathrm{C}$ until use. The concentration of crude protein extracts was determined using Protein Assay Dye Reagent Concentrate (Bio-Rad Laboratories, Hercules, CA).

Pollen Culture and nano-LC-MS analysis by C- AND SI-LIKe Treatments. Pollen grains of 'Banpeiyu' were cultured in the Citrus mature pollen culture system as described by Uchida et al. (2012a), for 4-h initial cultivation in the dark at $25^{\circ} \mathrm{C}$. Stylar crude protein extracts, derived from the styles of 'Hassaku' or 'Banpeiyu' were added into the medium to reach $50 \mu \mathrm{g} \cdot \mathrm{mL}^{-1}$ final concentration, as C- or SI-like treatment, respectively. Protein extraction buffer was added into the culture medium as a control. After 2-h treatments, 100 pollen tubes with normal development were picked up by glass capillary, according to the method described in the work of Hirano and Hoshino (2010), and transferred into new clean tubes. All pollen tubes were resuspended in $75 \mu \mathrm{L}$ of the extraction buffer containing 10-mm DL-dithiothreitol (DTT), 50-mм pH 8.0 Tris base, 10-mM ethylenediaminetetraacetic acid, 0.5\% 3-[(3cholamidopropyl)dimethylammonio]-1-propanesulfonate, and 0.5-mm phenylmethanesulfonyl fluoride (Sigma, St. Louis, MO). The samples mixed with micro glass beads (425 to 600 $\mu \mathrm{m}$ in diameter) were treated by vortex for $30 \mathrm{~s}$, and then kept in an ice bath for $30 \mathrm{~s}$; this process was repeated five times. The crude protein solution was then purified with a 2-D Clean-Up Kit (GE Healthcare Life Science, Little Chalfont, UK). The purified protein samples were dissolved in $50 \mu \mathrm{L}$ of $10-\mathrm{mm}$ DTT and $25-\mathrm{mm}$ $\mathrm{NH}_{4} \mathrm{HCO}_{3}$. Then, the samples were treated by reductive alkylation using a solution containing 55-mm iodoacetamide (Sigma) and 25-mм $\mathrm{NH}_{4} \mathrm{HCO}_{3}$ for $30 \mathrm{~min}$ at room temperature in the dark. Finally, the samples were treated by adding $50 \mu \mathrm{L}$ trypsin [10 ng. $\mathrm{mL}^{-1}$ (Sigma)] for $12 \mathrm{~h}$ at $37^{\circ} \mathrm{C}$, and diluted with formic acid to a final concentration of $0.1 \%$.

The protein samples were analyzed using nano-LC-MS (LTQ Orbitrap; Thermo Fisher Scientific, Waltham, MA), and spectra were processed and exported by extract_msn.exe program (BioWorks 3.2 software; Thermo Fisher Scientific). Extracted spectra were internally calibrated using trypsin autoproteolysis products. Protein identification was accomplished by comparing the mass list with the Citrus database in NCBI using MASCOT software (version 2.2; Matrix Science, Boston, MA). The proteins detected in the control were excluded in both C- and SI-like treatments.

EXPRESSION ANALYSIS OF CANDIDATE GENES RELATED TO SI-LIKE RESPONSE BY SQRT-PCR AND QRT-PCR. 'Banpeiyu' and 'Hyuganatsu' pollen grains were resuspended in the Citrus mature pollen culture system at a density of $\approx 10^{6}$ grains $/ \mathrm{mL}$ for $4 \mathrm{~h}$ of initial cultivation at $25^{\circ} \mathrm{C}$ in the dark. Pollen tubes of 'Banpeiyu' were exposed to 'Banpeiyu' or 'Hyuganatsu' stylar crude protein extracts as SI- or C-like treatment, respectively; vice versa, 'Hyuganatsu' pollen tubes were exposed to 'Banpeiyu' or 'Hyuganatsu' stylar crude protein extracts as C- or SI-like treatment, respectively.

The pollen tubes of 'Banpeiyu' and 'Hyuganatsu' were collected after $0,1,2$, and $4 \mathrm{~h}$ of C-and SI-like treatments. Total RNA was extracted by RNeasy Plant Mini Kit (Qiagen, Venlo, The Netherlands), and cDNA were synthesized from $1 \mu \mathrm{g}$ of total RNA using the Superscript III kit (Life Technologies, Carlsbad, CA) with Oligo $(\mathrm{dT})_{20}$ primers. The primer sequences of putative SI-related genes in Citrus, including $\mathrm{Cu} / \mathrm{Zn} S O D$ (AB981053), iron SOD [Fe SOD (AB981054)], Mn SOD (AB981055), CAT (AB981056), CYP (AB981057), L-galactose-1-phosphate phosphatase [GPP (AB981061)], miraculinlike protein-1 [MLP-1 (AB981059)], and MLP-3 (AB981060) were obtained, and gene expressions after 4-h C- and SI-like treatments were analyzed by semiquantitative reverse transcription polymerase chain reaction (SqRT-PCR). The primer sequences and SqRT-PCR procedures are listed in Table 1. Citrus constitutively expressed the actin gene of 'Banpeiyu' (accession no. GU911361) and 'Hyuganatsu' (accession no. XM_006432422) as an internal control. Real-time qRT-PCR was performed by a CFX manager real-time PCR detection system (Bio-Rad Laboratories) using the SYBR Fast qRT-PCR Kit (KapaBiosystems, Wilmington, MA) and corresponding primers (Table 2). The data were analyzed using CFX manager software (Bio-Rad Laboratories) using the $2^{-\triangle \triangle \mathrm{CT}}$ method. The 
Table 1. Primers and PCR procedures used for semiquantitative reverse transcription PCR (SqRT-PCR).

\begin{tabular}{|c|c|c|}
\hline Primer name & Primer sequences $\left(5^{\prime}-3^{\prime}\right)$ & Procedure for SqRT-PCR \\
\hline \multirow{2}{*}{$\begin{array}{l}\text { Copper/zinc superoxide } \\
\text { dismutase }(\mathrm{Zn} / \mathrm{Cu} \mathrm{SOD})\end{array}$} & For: AGCAGTTGCAGTTCTTGGTG & $94{ }^{\circ} \mathrm{C}, 5 \mathrm{~min} ; 94{ }^{\circ} \mathrm{C} 30 \mathrm{~s}, 61^{\circ} \mathrm{C} 30 \mathrm{~s}, 72^{\circ} \mathrm{C} 60 \mathrm{~s}$, \\
\hline & Rev: CGTGGACTACAACAGCCCTT & 30 cycles; $72{ }^{\circ} \mathrm{C} 10 \mathrm{~min}$ \\
\hline Iron SOD (Fe SOD) & For: AGAAAGACTGGTGGCCGAAT & $94{ }^{\circ} \mathrm{C}, 5 \mathrm{~min} ; 94{ }^{\circ} \mathrm{C} 30 \mathrm{~s}, 60^{\circ} \mathrm{C} 30 \mathrm{~s}, 72^{\circ} \mathrm{C} 60 \mathrm{~s}$, \\
\hline \multirow[t]{2}{*}{ Manganese SOD (Mn SOD) } & For: CGATTACAGCGCTTTGGAGC & $94{ }^{\circ} \mathrm{C}, 5 \mathrm{~min} ; 94{ }^{\circ} \mathrm{C} 30 \mathrm{~s}, 59^{\circ} \mathrm{C} 30 \mathrm{~s}, 72^{\circ} \mathrm{C} 60 \mathrm{~s}$, \\
\hline & Rev: GCACCCTCAGCACTCATCTT & 30 cycles; $72{ }^{\circ} \mathrm{C} 10 \mathrm{~min}$ \\
\hline Catalase $(C A T)$ & For: TTGTCCGCTTCTCCACTGTT & $94{ }^{\circ} \mathrm{C}, 5 \mathrm{~min} ; 94{ }^{\circ} \mathrm{C} 30 \mathrm{~s}, 58^{\circ} \mathrm{C} 30 \mathrm{~s}, 72^{\circ} \mathrm{C} 60 \mathrm{~s}$, \\
\hline \multirow[t]{2}{*}{ Cysteine protease $(C Y P)$} & For: TTGCTGATTGGAGCTGGGAA & $94{ }^{\circ} \mathrm{C}, 5 \mathrm{~min} ; 94{ }^{\circ} \mathrm{C} 30 \mathrm{~s}, 59^{\circ} \mathrm{C} 30 \mathrm{~s}, 72^{\circ} \mathrm{C} 60 \mathrm{~s}$, \\
\hline & Rev: GTACCCAACAGCAACGACAG & 30 cycles; $72{ }^{\circ} \mathrm{C} 10 \mathrm{~min}$ \\
\hline \multirow{2}{*}{$\begin{array}{c}\text { L-galactose-1-phosphate } \\
\text { phosphatase }(G P P)\end{array}$} & For: TCAAGCAGCAATTTCCCACG & $94{ }^{\circ} \mathrm{C}, 5 \mathrm{~min} ; 94{ }^{\circ} \mathrm{C} 30 \mathrm{~s}, 59^{\circ} \mathrm{C} 30 \mathrm{~s}, 72^{\circ} \mathrm{C} 60 \mathrm{~s}$, \\
\hline & Rev: CTTCCGCATGCAATTCCACA & 30 cycles; $72{ }^{\circ} \mathrm{C} 10 \mathrm{~min}$ \\
\hline \multirow[t]{2}{*}{ Miraculin-like protein-1 (MLP1) } & For: GGAATTAGCGCGGACAAAGG & $94{ }^{\circ} \mathrm{C}, 5 \mathrm{~min} ; 94{ }^{\circ} \mathrm{C} 30 \mathrm{~s}, 59^{\circ} \mathrm{C} 30 \mathrm{~s}, 72^{\circ} \mathrm{C} 60 \mathrm{~s}$, \\
\hline & Rev: CACAACTAGACGTTGGACGC & 40 cycles; $72{ }^{\circ} \mathrm{C} 10 \mathrm{~min}$ \\
\hline
\end{tabular}

Table 2. Primers and PCR procedures used for real-time quantitative PCR (qRT-PCR).

\begin{tabular}{|c|c|c|}
\hline Primer name & Primer sequences $\left(5^{\prime}-3^{\prime}\right)$ & Procedure for qRT-PCR \\
\hline \multirow{2}{*}{$\begin{array}{l}\text { Copper/zinc superoxide } \\
\quad \text { dismutase }(\mathrm{Zn} / \mathrm{Cu} \mathrm{SOD})\end{array}$} & For: AGGAAGCCTCTCTGGTCTCA & $94{ }^{\circ} \mathrm{C}, 5 \mathrm{~min} ; 94{ }^{\circ} \mathrm{C} 30 \mathrm{~s}, 61^{\circ} \mathrm{C} 30 \mathrm{~s}, 50$ cycles; $72{ }^{\circ} \mathrm{C} 10 \mathrm{~min}$ \\
\hline & Rev: CAGCAGGGTTAAAGTGGGGT & \\
\hline Iron SOD (Fe SOD) & For: GGAACTGAGCTTGGTGATGGA & $94{ }^{\circ} \mathrm{C}, 5 \mathrm{~min} ; 94^{\circ} \mathrm{C} 30 \mathrm{~s}, 60^{\circ} \mathrm{C} 30 \mathrm{~s}, 50$ cycles; $72{ }^{\circ} \mathrm{C} 10 \mathrm{~min}$ \\
\hline \multirow[t]{2}{*}{ Manganese SOD (Mn SOD) } & For: CGGAGGTCATGTCAACCACT & $94{ }^{\circ} \mathrm{C}, 5 \mathrm{~min} ; 94^{\circ} \mathrm{C} 30 \mathrm{~s}, 59^{\circ} \mathrm{C} 30 \mathrm{~s}, 50$ cycles; $72{ }^{\circ} \mathrm{C} 10 \mathrm{~min}$ \\
\hline & Rev: GCACCCTCAGCACTCATCTT & \\
\hline Catalase (CAT) & For: GGCGCTCCTGTATGGAACAA & $94{ }^{\circ} \mathrm{C}, 5 \mathrm{~min} ; 94{ }^{\circ} \mathrm{C} 30 \mathrm{~s}, 58^{\circ} \mathrm{C} 30 \mathrm{~s}, 50$ cycles; $72{ }^{\circ} \mathrm{C} 10 \mathrm{~min}$ \\
\hline \multirow[t]{2}{*}{ Cysteine protease $(C Y P)$} & For: AGCTTCGACGACTCCAATCC & $94{ }^{\circ} \mathrm{C}, 5 \mathrm{~min} ; 94^{\circ} \mathrm{C} 30 \mathrm{~s}, 59^{\circ} \mathrm{C} 30 \mathrm{~s}, 50$ cycles; $72{ }^{\circ} \mathrm{C} 10 \mathrm{~min}$ \\
\hline & Rev: CATACCTGCGAGCAAAACGG & \\
\hline \multirow{2}{*}{$\begin{array}{c}\text { L-galactose-1-phosphate } \\
\text { phosphatase }(G P P)\end{array}$} & For: AGAGGCTGGAACAAAACGTGA & $94{ }^{\circ} \mathrm{C}, 5 \mathrm{~min} ; 94^{\circ} \mathrm{C} 30 \mathrm{~s}, 59^{\circ} \mathrm{C} 30 \mathrm{~s}, 50$ cycles; $72{ }^{\circ} \mathrm{C} 10 \mathrm{~min}$ \\
\hline & Rev: TCCGCATGCAATTCCACAAA & \\
\hline
\end{tabular}

experiments of pollen tube treatments and expression analysis were repeated three times for statistical analysis, individually (Tukey's multiple range test).

ROS ANALYSIS IN POLLEN TUBES AFTER SI-LIKE TREATMENT. Pollen grains of 'Banpeiyu' and 'Hyuganatsu' were precultured for $4 \mathrm{~h}$ at $25^{\circ} \mathrm{C}$ in the Citrus mature pollen culture system in the dark. CM-H ${ }_{2}$ DCFDA (Life Technologies) was used for ROS visualization. The probe was diluted into anhydrous dimethyl sulfoxide to prepare 5- $\mu \mathrm{M}\left(\mathrm{CM}-\mathrm{H}_{2} \mathrm{DCFDA}\right)$ of working solution. Germinated pollen tubes were incubated with the probe in the dark for $30 \mathrm{~min}$ to load the probe into the pollen tubes. After labeling, the probe solution was discarded and pollen tubes were washed with culture medium three times. Then, pollen tubes were treated with C-and SI-like treatments for $2 \mathrm{~h}$. Fluorescence of ROS in pollen tubes was investigated with a confocal laser microscope (LSM700; Carl Zeiss, Jena, Germany).

\section{Results and Discussion}

In this study, we applied this SI-like response system for molecular identification of SI-related proteins in Citrus pollen tubes. To detect the SI-related proteins, we isolated the proteins from the 'Banpeiyu' pollen tubes treated with $\mathrm{C}$ and SI stylar crude protein extracts and obtained the peptide spectral data by nano-LC-MS analysis for the pollen tube proteins. As a result of searching the spectral data against the Citrus database, different protein expression was observed in the C-and SI-like treatments in comparison with the control, and we successfully identified 14 putative proteins induced by the C-like treatment (Table 3 ) and 27 putative proteins induced by the SI-like treatment (Table 4). All these proteins were classified according to Gene ontology terms relating to biological processes and molecular functions. In the C-like treatment, the metabolic process $(85.7 \%)$ was the most frequent category in the biological process, followed by the transport and glycolysis processes, which each accounted for another $7.15 \%$. For the molecular function, catalytic activity was the most frequent, accounting for $78.7 \%$; hydrolases activity, lipid binding, and calcium ion binding were each $7.1 \%$ (Fig. 1A). On the other hand, in the category of biological process for the SI-like treatment, metabolic process accounted for $85.2 \%$, followed by the stress-response process, which accounted for $11.1 \%$, and the glycolysis process, which accounted for the rest. For the molecular function category, catalytic activity was also the most frequent activity, accounting for $74.1 \%$, followed by hydrolase activity (14.8\%); the rest was divided equally among calcium ion binding, adenosine triphosphate binding, and pathogenesis-related protein (Fig. 1B). For the in vitro treatments, we added stylar crude proteins to the pollen culture medium instead of purified S-protein, so the proteins detected in both treatments, such as those in metabolic process, were thought not to relate to 
Table 3. Result of protein identification in Citrus maxima 'Banpeiyu' pollen tubes exposed to compatible (C)-like treatment.

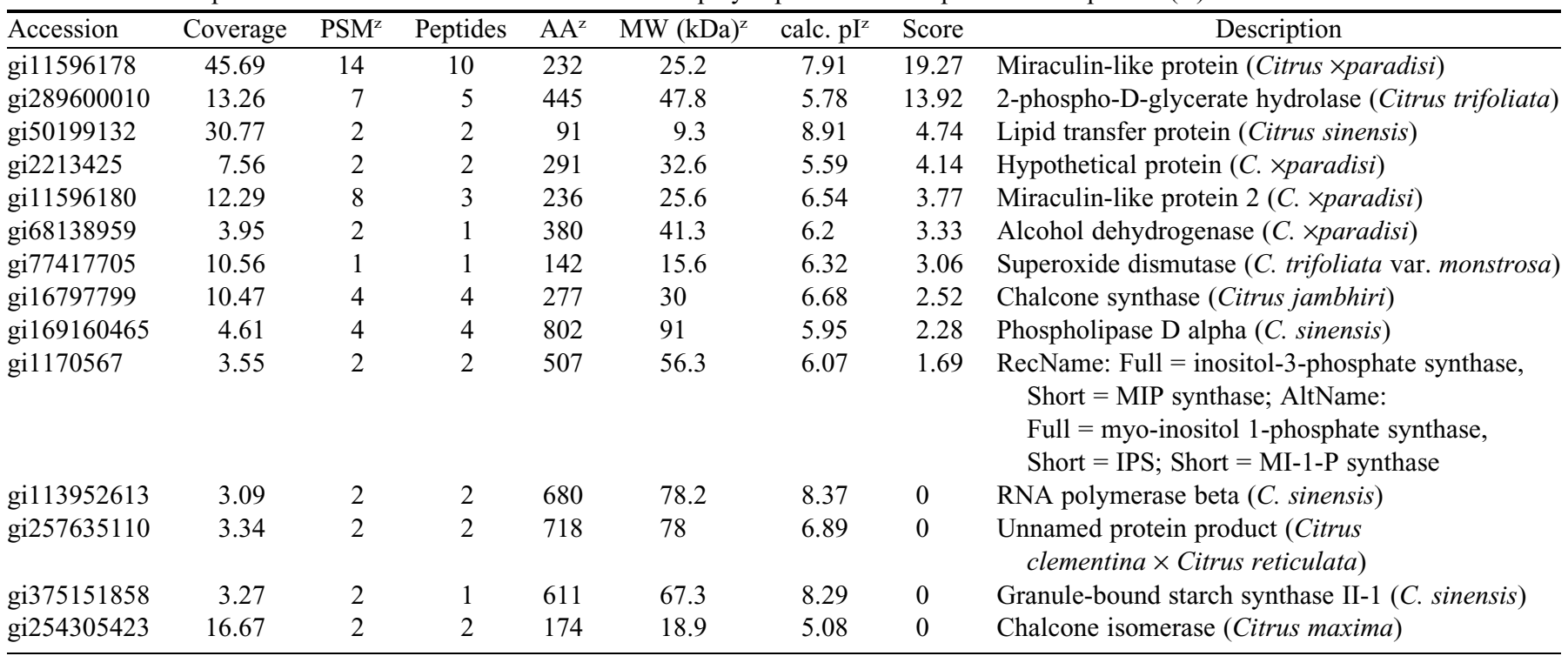

${ }^{\text {zPSM }}=$ peptide spectral matches; $\mathrm{AA}=$ amino acids; $\mathrm{MW}=$ molecular weight; calc. $\mathrm{pI}=$ calculated isoelectric point.

Table 4. Result of protein identification in Citrus maxima 'Banpeiyu' pollen tubes exposed to self-incompatible (SI)-like treatment.

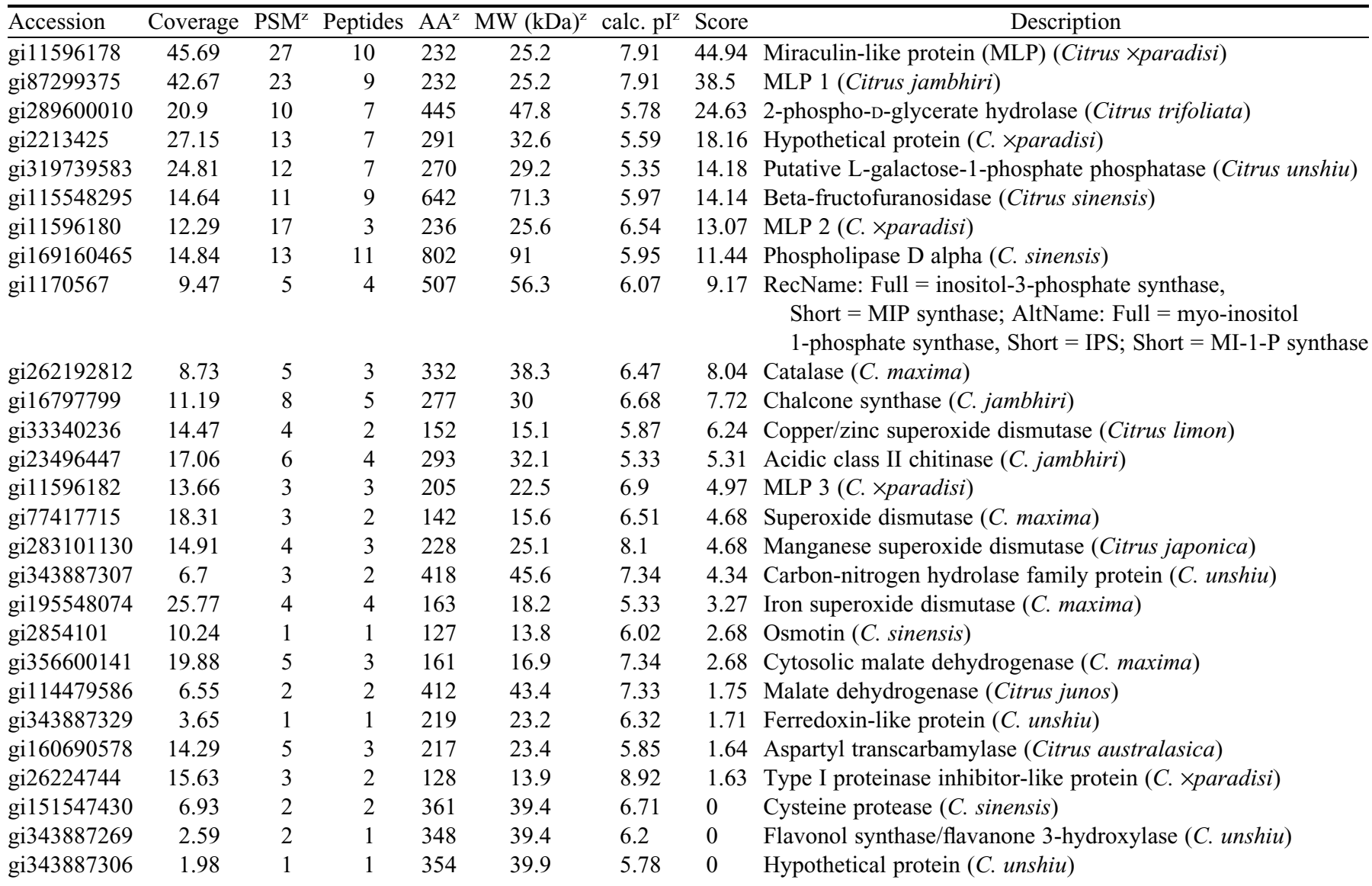

zPSM = peptide spectral matches; $\mathrm{AA}=$ amino acids; $\mathrm{MW}=$ molecular weight; calc. $\mathrm{pI}=$ calculated isoelectric point.

SI response. Since the "stress-response process" in the biological process category and the "pathogenesis-related protein" in the molecular function category were only observed in the SI-like treatment (Fig. 1B), we focused on these proteins as candidates for SI-related proteins.
We selected 8 genes, including $C u / Z n S O D, F e S O D, M n$ $S O D, C A T, C Y P, G P P, M L P-1$, and $M L P-3$, as candidates and investigated their expressions in the pollen tubes of 'Banpeiyu' and 'Hyuganatsu' after 4-h exposure to C- and SI-like treatments by SqRT-PCR (Fig. 2). The genes, $\mathrm{Cu} / \mathrm{Zn} \mathrm{SOD}, \mathrm{Fe} S O D$, 

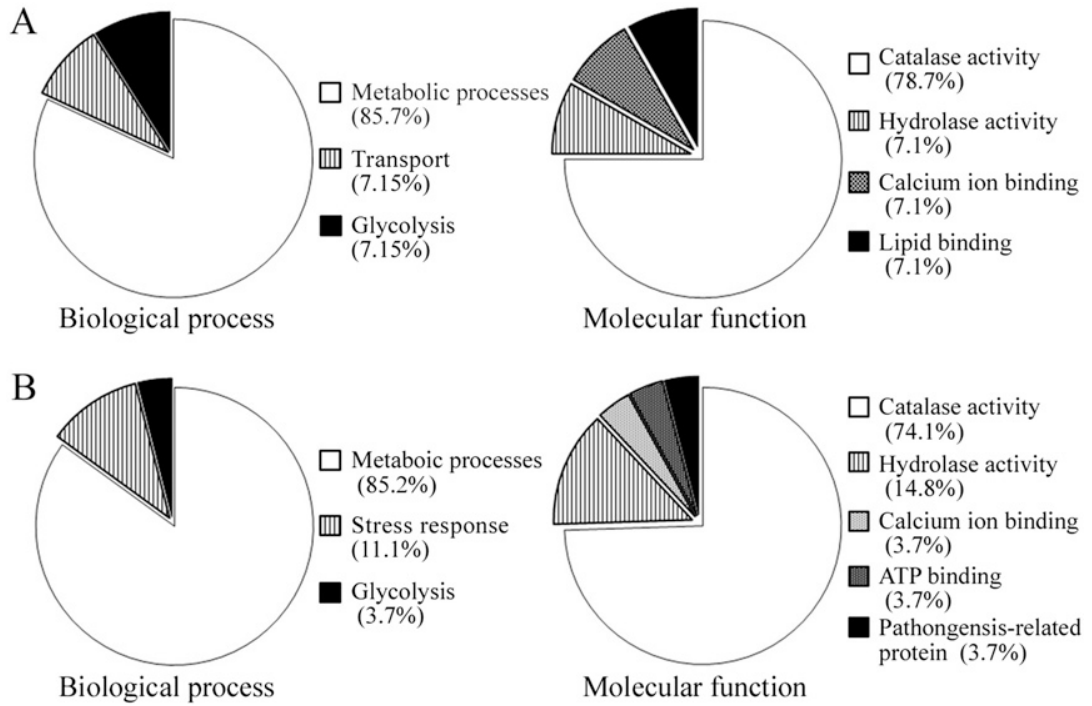

Fig. 1. Classification of the proteins from nano-liquid chromatography-mass spectrometry results in Citrus maxima 'Banpeiyu' pollen tubes after compatible-like (A) and self-incompatible-like (B) treatments. Protein classification is according to gene ontology terms related to biological process and molecular function.

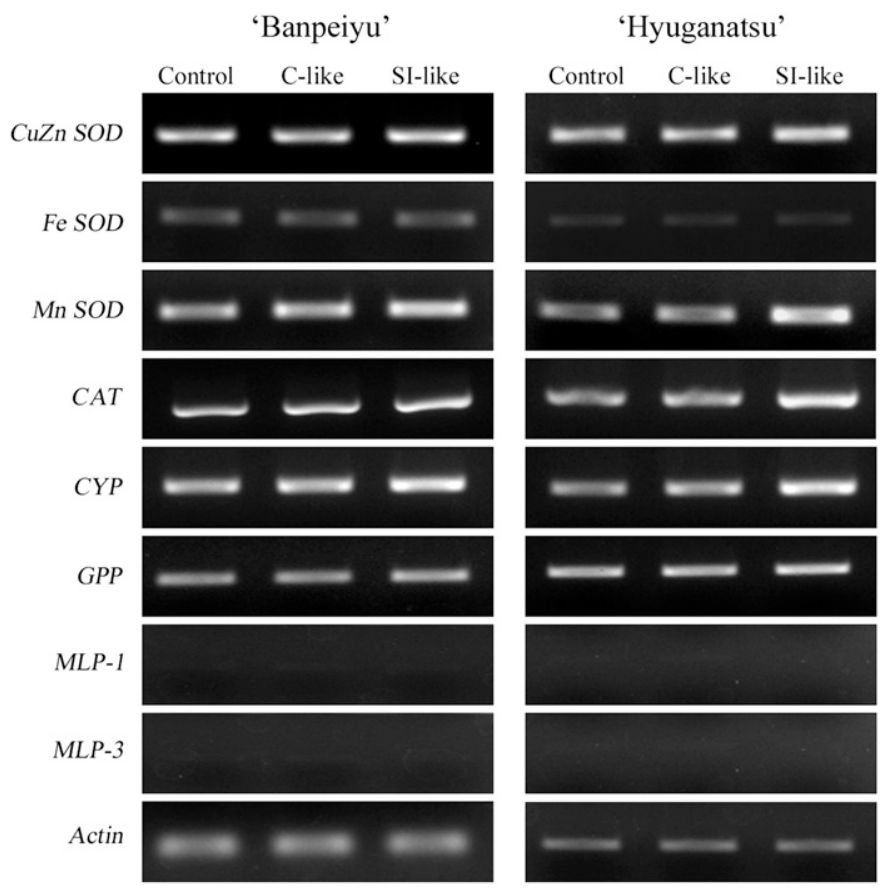

Fig. 2. Gene expression of candidates, copper/zinc superoxide dismutase ( $\mathrm{Cu} / \mathrm{Zn}$ $S O D)$, iron SOD (Fe SOD), manganese SOD (Mn SOD), catalase (CAT), cysteine protease $(C Y P)$, L-galactose-1-phosphate phosphatase (GPP), miraculin-like protein-1 (MLP-1), and miraculin-like protein-3 (MLP-3), related to self-incompatible (SI) response in Citrus maxima 'Banpeiyu' and C. tamurana 'Hyuganatsu' pollen tubes after $4 \mathrm{~h}$ of compatible (C)-like and SI-like treatments. The gene expressions were analyzed by semiquantitative reverse transcription PCR.

Mn SOD, CAT, CYP, and GPP, were expressed in the pollen tubes of both 'Banpeiyu' and 'Hyuganatsu' regardless of the treatment. On the other hand, we could not detect expression of $M L P-1$ and $M L P-3$ in both 'Banpeiyu' and 'Hyuganatsu'. Therefore, six genes, $C u / Z n S O D, F e S O D, M n S O D$,
$C A T, C Y P$, and $G P P$, were chosen for further investigation. We analyzed the expression levels in the pollen tubes during the $\mathrm{C}$ - or SI-like treatments by qRT-PCR. The expression profiles in 'Banpeiyu' (Fig. 3A) and 'Hyuganatsu' (Fig. 3B) showed similar trends, and the expression levels of $\mathrm{Cu} / \mathrm{Zn}$ $S O D, M n S O D, C A T$, and $C Y P$ after the SI-like treatment from 2 to $4 \mathrm{~h}$ were higher than those after the C-like treatment or control, except for $M n S O D$ and $C Y P$ in 'Banpeiyu' after 2-h SI-like treatment. In Mn SOD of 'Banpeiyu' and 'Hyuganatsu', the expression levels after 4-h C-like treatment were also higher than those after control treatment. The expression levels of $\mathrm{Fe} S O D$ in both 'Banpeiyu' and 'Hyuganatsu' pollen tubes showed no significant changes throughout 4-h C- and SI-like treatments. Although $G P P$ expression level with 1-h SI-like treatment in 'Hyuganatsu' was higher than with C-like treatment and control, there was no significant difference from 2 to $4 \mathrm{~h}$.

In the candidates, the gene expressions of $C A T, C u / Z n S O D$, and $M n S O D$ were increased in the pollen tubes of 'Banpeiyu' and 'Hyuganatsu' by the SI-like treatment (Fig. 3). SODs (EC1.15.1.1) are a family of metalloenzymes that generally exist in vegetative and reproductive plant tissues as scavengers that protect cells against oxidative stress and maintain a balance between ROS generation and degradation (del Río et al., 2002; Wang et al., 2009b). CAT, as an antioxidant enzyme, can effectively convert $\mathrm{H}_{2} \mathrm{O}_{2}$ into $\mathrm{H}_{2} \mathrm{O}$ and $\mathrm{O}_{2}$ following the reaction of SODs. Therefore, it was predicted that ROS in the pollen tubes would correlate with the SI-like response. We investigated the ROS level changes after $\mathrm{C}$-and SI-like treatments in 'Banpeiyu' and 'Hyuganatsu' pollen tubes. We detected the levels by ROS probe, CM$\mathrm{H}_{2}$ DCFDA. Levels in the pollen tubes of 'Banpeiyu' and 'Hyuganatsu' were quite low in the control and C-like treatment (Fig. 4). On the other hand, the pollen tubes after SI-like treatment showed strong fluorescent signals in both 'Banpeiyu' and 'Hyuganatsu' (Fig. 4). These results suggest that ROS production is not induced by the addition of stylar crude proteins to the culture medium, but is caused by the reaction between specific proteins from the styles and some kind of factor in the pollen tubes.

ROS is an important signal molecule in plants and participates in cell signaling networks (Gadjev et al., 2008). In the pollen tubes of $P$. rhoeas, it has been reported that ROS increase is induced by the SI response following $\mathrm{Ca}^{2+}$ oscillations and that the depolymerization of actin in pollen tube cytoskeletons was also detected shortly thereafter (Wilkins et al., 2011). In 'Banpeiyu' and 'Hyuganatsu', ROS increase is also thought to be one of the key phenomena in the SI-like response, and the expression increases of $C A T$ and $S O D$ s would be a feedback response to excessive ROS generation. In addition to the $C A T$ and $S O D$ s, the expression level of CYP increases after SI-like treatment (Fig. 3). CYP is associated with the stress response (Bernoux et al., 2008; Chen et al., 2010), and high expression of CYP is considered an indicator of the early stages of PCD (Kuriyama and Fukuda, 2002). Since ROS has been proposed as a key inducer of PCD (De Pinto et al., 2012), it is possible that 
A
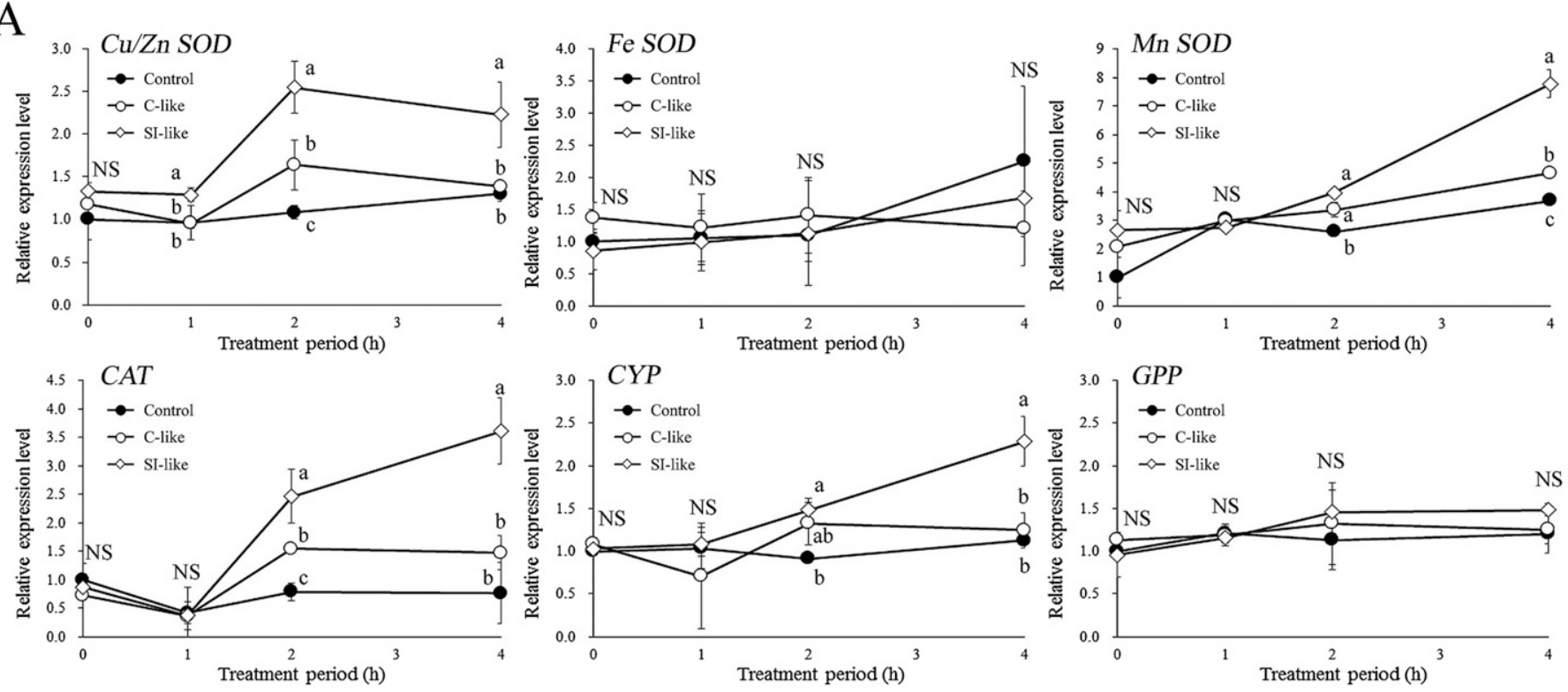

B
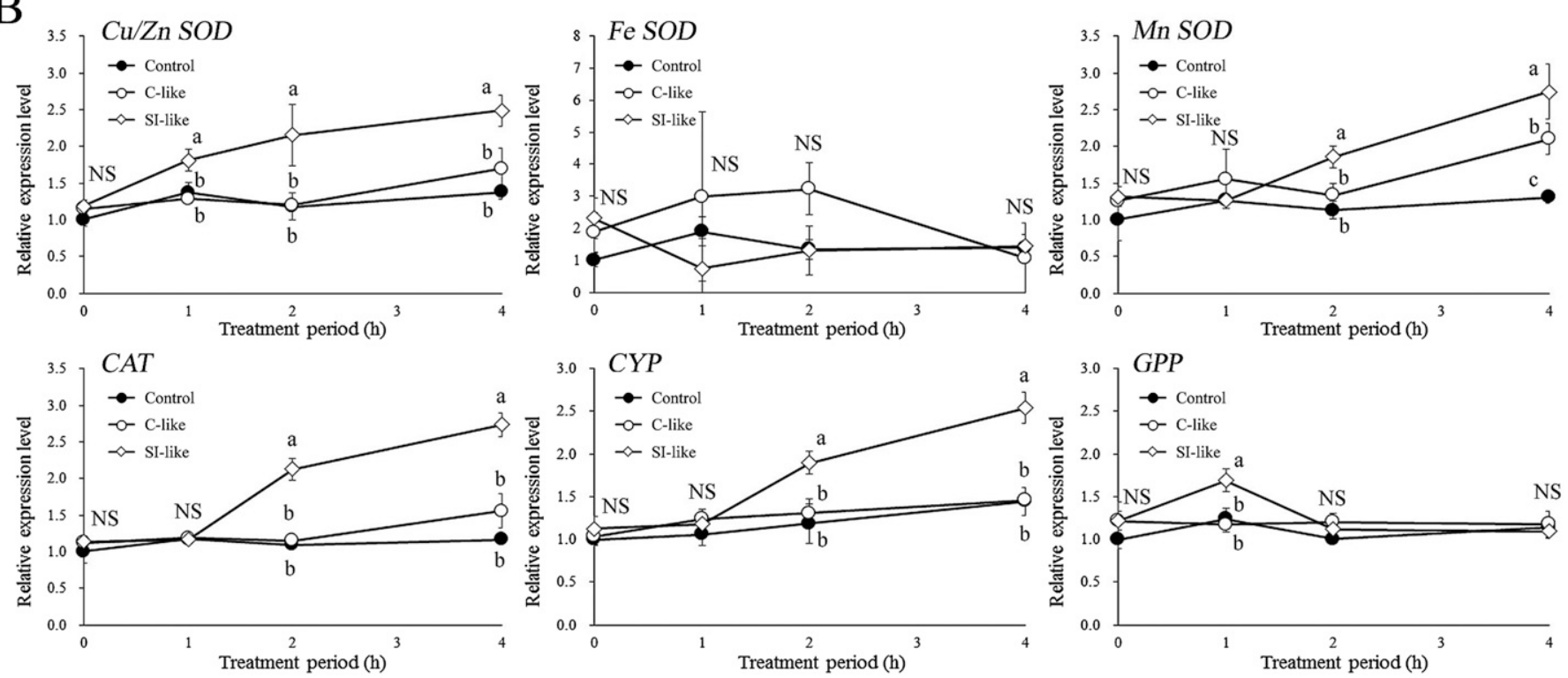

Fig. 3. Gene expression changes during compatible (C)-like and self-incompatible (SI)-like treatments. The pollen tubes of Citrus maxima 'Banpeiyu' (A) and Citrus tamurana 'Hyuganatsu' (B) were processed with C- or SI-like treatment for 0-4h, and then the gene expression in the pollen tubes were analyzed by realtime quantitative PCR for Copper/zinc superoxide dismutase (Cu/Zn SOD), iron SOD (Fe SOD), manganese SOD (Mn SOD), catalase (CAT), cysteine protease $(C Y P)$, and L-galactose-1-phosphate phosphatase $(G P P)$. Values are the mean of three biological replicates \pm SD for each timing $(n=3)$. Different letters represent significant differences at 5\% level as determined by Tukey's multiple range test (NS = nonsignificant difference).
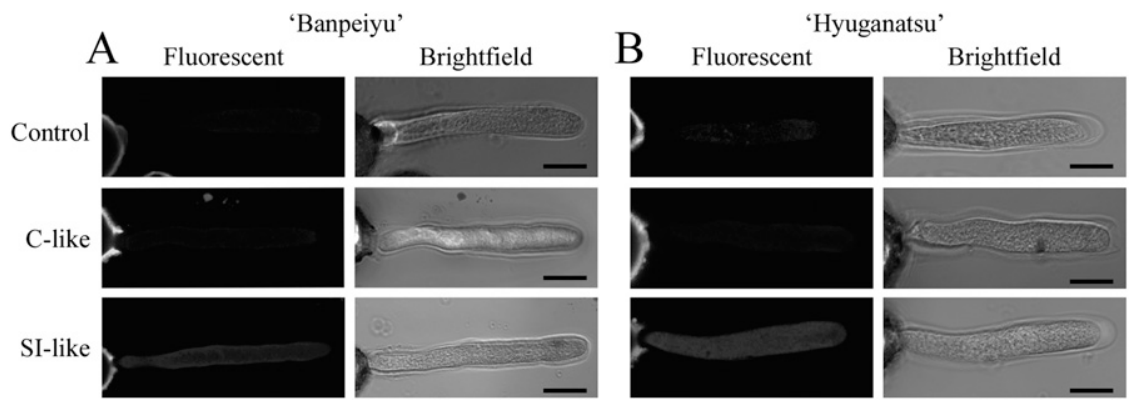

Fig. 4. Effect of 2-h compatible (C)-like or self-incompatible (SI)-like treatments on reactive oxygen species level in Citrus maxima 'Banpeiyu' (A) and Citrus tamurana 'Hyuganatsu' (B) pollen tubes; Scale bar $=200 \mu \mathrm{m}$. the ROS cascade reaction, which was induced by SI-like treatment in 'Banpeiyu' and 'Hyuganatsu' pollen tubes, is a trigger for the PCD process.

The $S$ genotype of 'Banpeiyu' has been determined as $S_{1} S_{2}$ by number of pollination experiments, and the $S$ genotype of 'Hassaku' has been estimated as $S_{4} S_{5}$ (Kim et al., 2011). Therefore, in this study, the candidates for SI-related proteins derived from the differences between SI- and C-like treatments with different $S$ genotypes. The $S$ genotype of 'Hyuganatsu' is $S_{1} S_{?}$ and is known as 
not including $S_{2}$ allele (Kim et al., 2011). In expression analysis, C-like setting of 'Banpeiyu' $\left(S_{1} S_{2}\right)$ and 'Hyuganatsu' $\left(S_{1} S_{2}\right)$ is interpreted as a semicompatible genotype. The gene expressions of SODs, CAT, and CYP showed significant differences between $\mathrm{C}$ - and SI-like treatments (Fig. 3), suggesting that the in vitro SI-like system would be applicable for $S$ genotyping analysis in Citrus.

In conclusion, we successfully identified the proteins related to SI-like response by combining an in vitro SI-like response system and nano-LC-MS analysis, and revealed that ROS generation in the pollen tubes is an SI-like response. The gene expressions of CAT and SODs were increased in the pollen tubes by the SI-like treatment, also indicating that oxidative balance in Citrus pollen tubes is disrupted by the SI-like treatment. To clarify the SI mechanism in Citrus, further study of the SI response in pollen tubes is needed. In addition, the female and male determinants for SI need to be identified. The SI-like system has great potential for progressing our understanding of the SI response.

\section{Literature Cited}

Bernoux, M., T. Timmers, A. Jauneau, C. Briere, P.J. de Wit, Y. Marco, and L. Deslandes. 2008. RD19, an Arabidopsis cysteine protease required for $\mathrm{RRS}_{1}$-R-mediated resistance, is relocalized to the nucleus by the Ralstonia solanacearum PopP $_{2}$ effector. Plant Cell 20:2252-2264.

Chen, H.J., C.T. Su, C.H. Lin, G.J. Huang, and Y.H. Lin. 2010. Expression of sweet potato cysteine protease SPCP2 altered developmental characteristics and stress responses in transgenic Arabidopsis plants. J. Plant Physiol. 167:838-847.

De Pinto, M., V. Locato, and L. De Gara. 2012. Redox regulation in plant programmed cell death. Plant Cell Environ. 35:234-244.

del Río, L.A., F.J. Corpas, L.M. Sandalio, J.M. Palma, M. Gomez, and J.B. Barroso. 2002. Reactive oxygen species, antioxidant systems and nitric oxide in peroxisomes. J. Expt. Bot. 53:1255-1272.

Distefano, G., M. Caruso, S. La Malfa, A. Gentile, and E. Tribulato. 2009. Histological and molecular analysis of pollen-pistil interaction in clementine. Plant Cell Rpt. 28:1439-1451.

Foote, H.C., J.P. Ride, V.E. Franklin-Tong, E.A. Walker, M.J. Lawrence, and F.C. Franklin. 1994. Cloning and expression of a distinctive class of self-incompatibility $(S)$ gene from Papaver rhoeas L. Proc. Natl. Acad. Sci. USA 91:2265-2269.

Fuchs, Y. and H. Steller. 2011. Programmed cell death in animal development and disease. Cell 147:742-758.

Gadjev, I., J.M. Stone, and T.S. Gechev. 2008. Programmed cell death in plants: New insights into redox regulation and the role of hydrogen peroxide. Intl. Rev. Cell Mol. Biol. 270:87-144.

Geitmann, A., B.N. Snowman, A.M.C. Emons, and V.E. FranklinTong. 2000. Alterations in the actin cytoskeleton of pollen tubes are induced by the self-incompatibility reaction in Papaver rhoeas. Plant Cell 12:1239-1251.

Gray, J. 2004. Programmed cell death in plants. Blackwell Publishing, Oxford, UK.

Hirano, T. and Y. Hoshino. 2010. Capture of male gamete dynamics in pollen tubes, p. 127-134. In: B.J. Kaiser (ed.). Pollen: Structure, types and effects. Nova Sci., Hauppauge, NY.

Hiratsuka, S., M. Fujimura, T. Hayashida, Y. Nishikawa, and K. Nada. 2012. Pollen factors controlling self-incompatibility strength in japanese pear. Sex. Plant Reprod. 25:347-352.

Kim, J.H., T. Mori, A. Wakana, B.X. Ngo, K. Sakai, and K. Kajiwara. 2011. Determination of self-incompatible Citrus cultivars with $S_{I}$ and/or $S_{2}$ alleles by pollination with homozygous $\mathrm{S}_{1}$ seedlings $\left(S_{1} S_{1}\right.$ or $S_{2} S_{2}$ ) of 'Banpeiyu'. Pummelo. J. Jpn. Soc. Hort. Sci. 80:404-413. Kuriyama, H. and H. Fukuda. 2002. Developmental programmed cell death in plants. Curr. Opin. Plant Biol. 5:568-573.
Lai, Z., W. Ma, B. Han, L. Liang, Y. Zhang, G. Hong, and Y. Xue. 2002. An F-box gene linked to the self-incompatibility $(S)$ locus of Antirrhinum is expressed specifically in pollen and tapetum. Plant Mol. Biol. 50:29-42.

Lee, H.S., S. Huang, and T. Kao. 1994. S proteins control rejection of incompatible pollen in Petunia inflata. Nature 367:560-563.

Li, Y., A. Abe, A. Uchida, A. Yamamoto, T. Hirano, and H. Kunitake. 2015. Effects of polyamines on self-incompatibility-like responses in pollen tubes of Citrus cultivars, Banpeiyu and Hyuganatsu. J. Amer. Soc. Hort. Sci. 140:183-190.

Meng, D., Z. Gu, H. Yuan, A. Wang, W. Li, Q. Yang, Y. Zhu, and T. Li. 2014. The microtubule cytoskeleton and pollen tube Golgi vesicle system are required for in vitro S-RNase internalization and gametic self-incompatibility in apple. Plant Cell Physiol. 55:977-989.

Miao, H.X., Y.H. Qin, J.A. Teixeira da Silva, Z.X. Ye, and G.B. Hu. 2011. Cloning and expression analysis of $S$-RNase homologous gene in Citrus reticulata Blanco cv. Wuzishatangju. Plant Sci. 180:358-367.

Murfett, J., T.L. Atherton, B. Mou, C.S. Gasser, and B.A. McClure. 1994. S-RNase expressed in transgenic Nicotiana causes S-allelespecific pollen rejection. Nature 367:563-566.

Rentel, M.C. and M.R. Knight. 2004. Oxidative stress-induced calcium signaling in Arabidopsis. Plant Physiol. 135:1471-1479.

Roldán, J.A., H.J. Rojas, and A. Goldraij. 2012. Disorganization of F-actin cytoskeleton precedes vacuolar disruption in pollen tubes during the in vivo self-incompatibility response in Nicotiana alata. Ann. Bot. 110:787-795.

Serrano, I., M.C. Romero-Puertas, M. Rodríguez-Serrano, L.M. Sandalio, and A. Olmedilla. 2011. Peroxynitrite mediates programmed cell death both in papillar cells and in self-incompatible pollen in the olive (Olea europaea L.). J. Expt. Bot. 63:1479-1493. Thomas, S.G. and V.E. Franklin-Tong. 2004. Self-incompatibility triggers programmed cell death in Papaver pollen. Nature 429:305-309.

Uchida, A., A. Abe, Y. Hoshino, and H. Kunitake. 2012a. Liquid culture system for mature pollen in Hyuganatsu (Citrus tamurana hort. ex Tanaka). Hort. Res. (Japan) 11:173-179.

Uchida, A., S. Takenaka, Y. Sakakibana, S. Kurogi, C. Honsho, H. Sassa, M. Suiko, and H. Kunitake. 2012b. Comprehensive analysis of expressed proteins in the different stages of the style development of self-incompatible 'Hyuganatsu' (Citrus tamurana hort. ex Tanaka). J. Jpn. Soc. Hort. Sci. 81:150-158.

Wakana, A., B.X. Ngo, I. Fukudome, and K. Kejiwara. 2004. Estimation of the degree of self-incompatibility reaction during flower bud development and production of self-fertilized seeds by bud pollination in self-incompatible Citrus cultivars. J. Faculty Agr. Kyushu Univ. 49:307-320.

Wang, C., J. Wu, G. Xu, Y. Gao, G. Chen, J. Wu, H. Wu, and S. Zhang. 2010. S-RNase disrupts tip-localized reactive oxygen species and induces nuclear DNA degradation in incompatible pollen tubes of Pyrus pyrifolia. J. Cell Sci. 123:4301-4309.

Wang, C., G. Xu, X. Jiang, G. Chen, J. Wu, H. Wu, and S. Zhang. 2009a. S-RNase triggers mitochondrial alteration and DNA degradation in the incompatible pollen tube of Pyrus pyrifolia in vitro. Plant J. 57:220-229.

Wang, J., X. Liu, and G. Yu. 2009b. Identification of superoxide dismutase isoenzymes in tobacco pollen. Front. Biol. China 4:442445 .

Wheeler, M.J., B.H. de Graaf, N. Hadjiosif, R.M. Perry, N.S. Poulter, K. Osman, S. Vatovec, A. Harper, F.C. Franklin, and V.E. FranklinTong. 2009. Identification of the pollen self-incompatibility determinant in Papaver rhoeas. Nature 459:992-995.

Wilkins, K.A., J. Bancroft, M. Bosch, J. Ings, N. Smirnoff, and V.E. Franklin-Tong. 2011. Reactive oxygen species and nitric oxide mediate actin reorganization and programmed cell death in the self-incompatibility response of Papaver. Plant Physiol. 156:404416.

Yamamoto, M., T. Kubo, and S. Tominaga. 2006. Self-and crossincompatibility of various Citrus accessions. J. Jpn. Soc. Hort. Sci. 75:372-378. 